This item was submitted to Loughborough's Research Repository by the author.

Items in Figshare are protected by copyright, with all rights reserved, unless otherwise indicated.

\title{
Consumers' ethical perceptions of social media analytics practices: risks, benefits and potential outcomes
}

PLEASE CITE THE PUBLISHED VERSION

https://doi.org/10.1016/j.jbusres.2018.12.008

PUBLISHER

(C) Elsevier

VERSION

AM (Accepted Manuscript)

\section{PUBLISHER STATEMENT}

This paper was accepted for publication in the journal Journal of Business Research and the definitive published version is available at https://doi.org/10.1016/j.jbusres.2018.12.008.

LICENCE

CC BY-NC-ND 4.0

\section{REPOSITORY RECORD}

Michaelidou, Nina, and Milena Micevski. 2019. "Consumers' Ethical Perceptions of Social Media Analytics Practices: Risks, Benefits and Potential Outcomes”. figshare. https://hdl.handle.net/2134/36491. 


\title{
Consumers' Ethical Perceptions of Social Media Analytics Practices: Risks, Benefits and Potential Outcomes
}

\begin{abstract}
The increased leveraging of social media by organizations to derive business value has created concerns about the practice of social media analytics (SMA). While SMA may be beneficial for organizations and consumers alike, there is concern that it is not practiced with ethical care. In this study, we identify and model outcomes of ethical perceptions of SMA practices and organizational trustworthiness with data collected from 316 social media users. We also examine the roles of perceived risk and benefits in facilitating, or not, these outcomes. Results show that unfavorable ethical perceptions of SMA practices and low trustworthiness lead to perceived risk of sharing information, and subsequently to negative outcomes such as, unwillingness to reveal and falsification of information, as well as taking actions against organizations. We also find that perceived benefits moderate the relationship between perceived risk of sharing information and outcomes. The findings have significant theoretical implications and practical utility for organizations.
\end{abstract}

Keywords: Social Media Analytics; Ethical Perceptions, Ethics, Perceived Risk; Justice Theory 


\section{Introduction}

Technological advancements have altered the way in which individuals share information with others, and communicate with organizations and brands (Zhang \& Mao, 2016). In 2017 there were about two billion active Facebook users, generating four new petabytes of data per day (Brandwatch, 2018a). Statistics from GlobalWebIndex indicate that 53\% and 50\% of Instagram and Twitter users, respectively, follow brands (Mander, 2015). Additionally, anecdotal evidence shows that $91 \%$ of retail brands and $81 \%$ of SMEs use social media platforms, integrating them into their communication and customer service strategies (Dua, 2016). As the ecology of social media encourages co-creation, participation and engagement with brand content (Smith, Fischer \& Yongjian, 2012), organizations have devised strategies to motivate and engage social media users even further on these platforms, in order to create brand conversations (Saboo, Kumar \& Ramani, 2016). Interestingly though, $96 \%$ of individuals that talk about brands on social media do not follow brand profiles (Brandwatch, 2018b). Indeed, prior research has shown that most individuals tend to talk about the brands they own or are interested in on social media. Furthermore, individuals also talk about their experiences with brands on SNS, including both positive and negative experiences (Michaelidou, Christodoulides \& Kilic, 2016).

The proliferation of social media and the tendency of consumers to share their brand experiences on those platforms has given rise to the recent 'ethically questionable' organizational practices involving the collection of content from social media (DiStaso \& Bortree, 2014). Such practices present an excellent source of insight for organizations that engage in social media analytics (SMA). SMA refers to the acquisition, analysis and dissemination of brand-relevant or personal information (e.g., consumer opinions, posts, and metadata such as demographic information) from social media sites to assist with business decisions and strategies (Hajli \& Lin, 2016; Holsapple, Hsiao \& Pakath, 2014). SMA is 
performed on social media platforms such as Twitter (SNS) and blogs, which nowadays represent 'massive fields' of unobtrusive data (Gleibs, 2014). While such practices are beneficial for the organizations (Punj, 2017), they raise privacy and/or ethical concerns among consumers/social media users and/or other stakeholders (e.g., government and policy makers), as most often data or information is collected unobtrusively, without the knowledge or consent of the user (Hajli \& Lin, 2016; Martin, 2015).

Specifically, privacy online is currently a highly topical issue (e.g., GDPR, 2018'; Le \& Liaw, 2017), with consumers viewing the collection and use of their information for corporate purposes as an invasion of their privacy, and as an unethical or unfair practice (Hajli \& Lin, 2016). Previous research has also identified particular actions which consumers are likely to take to protect themselves from or retaliate against such apparently unfair practices, such as boycotts, the refusal to provide information and the falsification of information, as well as registering complaints (Bechwati \& Morrin, 2003; Cohn, 2010; Gregoire \& Fisher, 2008).

Despite the above concerns, much of the recent academic research on social media focuses primarily on the characteristics and peculiarities of social media platforms and how these platforms are leveraged by organizations to engage consumers with their brands (see Hudson, Huang, Roth \& Madden, 2016). Potential ethical concerns are also discussed but often within the context of 'organization-customer' interactions (e.g., Punj, 2017). This reflects a serious gap in the business and marketing literature, as social media present viable platforms for organizations to perform SMA, which importantly cannot be confined within the rubric of the 'organization-customer' interface. Additionally, SMA is a relatively new organizational practice for which ethical considerations have yet to be discussed in the literature. Nevertheless, ethical considerations of organizational practices are important as

\footnotetext{
1 The General Data Protection Regulation (GDPR) is a regulation concerning data protection and privacy, recently implemented (25/05/2018) in EU law.
} 
they drive negative outcomes (Brunk, 2010; Crane, 2005), thus presenting a strong impetus for research into this domain.

In view of these gaps, this study is the first to conceptualize and empirically test a model which identifies the outcomes of ethical perceptions of SMA practices and organizational trustworthiness. Our study is original and contributes to theory as follows: First, we examine SMA using an 'ethics lens', therefore increasing the profile and role of ethics in this relatively new and 'ethically unchallenged' organizational practice. This is an imminent and timely topic, especially following the Cambridge Analytica and Facebook scandal that took place in 2018 (Hsu, 2018), and which indicated that SMA is not always necessarily performed with ethical care. Currently, the literature lacks an understanding of consumers' 'ethical stance' on SMA practices (Le \& Liaw, 2017), and while organizations are expected to operate with ethical care, this may not be the case. Therefore, as a practice seen as beneficial to both organizations and consumers (Culnan \& Bies, 2003), SMA should be subject to greater ethical scrutiny, since its processes (e.g., data collection and analysis) extend beyond brand-relevant information and organization-customer interactions.

Another contribution of our study is that it extends prior work on corporate practices that raise ethical concerns (e.g., Brunk, 2010). The current literature has neglected to include SMA as a practice which triggers ethical concerns. For example, Brunk's (2010) framework does not acknowledge SMA, while Le and Liaw (2017) focus on the advantages and disadvantages of such a practice, but overlook the ethical aspects. Our study, therefore, offers an incremental contribution by showing that consumers' ethical evaluation of SMA practices leads to perceived risk of sharing information on social media, and subsequently to negative outcomes. Additionally, in relation to other extant research (Le \& Liaw, 2017), we identify and model protective and retaliatory consumer actions (e.g., falsifying information and complaining) as outcomes of ethical perceptions and perceptions of trustworthiness, clarifying also the interacting roles of perceived risk and of the benefits of social media usage in this 
relationship. In this way, our study shows that what we believe about the ethicality of SMA and perceptions of trustworthiness do in fact hold true (e.g., they lead to negative outcomes) (Corley \& Gioia, 2011).

Moreover, our paper has a practical utility in that it has the potential to influence managerial practice (Corley \& Gioia, 2011). Given that organizations rely on SMA to inform business strategy and solve problems (Le \& Liaw, 2017; Punj, 2017), the risk perceptions of sharing information, as well as the truthfulness of such information, should be of great value and interest to organizations performing SMA in multiple sectors. To this end, organizations should be aware of consumers' ethical evaluation of their SMA practices and their potential outcomes (e.g., the falsification of information), in order to have a chance of addressing them.

The following sections present the background to the research and the theoretical framework. Subsequently, the methodology is presented, followed by the analysis and a discussion of the findings. The paper ends by addressing theoretical and practical implications, limitations and future research directions.

\section{Theoretical Background}

\subsection{Social Media Analytics (SMA) Practices and Justice Theory}

The collection and analysis of data from social media (i.e., SMA) is driven by organizations' attempts to remain competitive and the need to inform corporate and business strategy. However, such practices are likely to be seen as unjust or unfair. Justice is understood as key to the functioning of organizations, with fairness and ethicality being an expectation in interactions (Culnan \& Armstrong, 1999; Gross, 2008). Indeed, justice has been strongly linked to ethics through a focus on fairness and morality (Rupp et al., 2015) which organizations can echo in their information practices (Smith, Dinev \& Xu, 2011; Xu, 
Teo, Tan \& Agarwal, 2009). Justice theory serves as a good guide to understanding how ethical evaluations and trust are formed in relation to information practices and their potential outcomes (Ashworth \& Free, 2006; Smith et al., 2011). For example, Ashworth and Free (2006) adopt a normative approach to examine privacy as a result of organizational “dataveillance" practices, using justice theory notions.

More specifically, justice theory-which has been intertwined with moral and ethical views and ideas (e.g., Macklin, Martin \& Mathison, 2015)—encompasses distributive, interactional and procedural fairness perceptions. Perceptions concerning distributive fairness focus on the outcomes one receives (Culnan \& Bies, 2003), while interactional fairness addresses the treatment one obtains in interpersonal relationships (Bies \& Moag, 1986). Finally, perceptions of procedural fairness reflect the extent to which the procedures and practices an organization adopts are seen as fair or just, and how they form part of its obligations and duties to its stakeholders, including consumers (Culnan \& Bies, 2003).

Moreover, justice theory is most relevant in the study of SMA practices and procedures, which are typically performed outside of the organizational-consumer interpersonal interface and without the knowledge of consumers or social media users, thus raising ethical or privacy concerns (Ashworth \& Free, 2006; Hajli \& Lin, 2016). Specifically, within the context of SMA practices, justice theory epitomizes the fairness of the procedures an organization adopts in collecting and analyzing social media data for business decisions, which are linked to perceptions of trust (Smith et al., 2011). Fairness perceptions regarding such organizational procedures (e.g., SMA) are said to have a psychological impact on individuals that often surpasses any concern for the material gains or outcomes one receives (e.g., distributive justice) (Güth, Schmittberger \& Schwarze, 1982). For example, gains acquired from using social media may constitute a form of distributive justice, whereby social media users can fulfil their need for information seeking, self-expression and entertainment (Courtois, Mechant, Marez \& Verlege, 2009) at no financial cost. In other words, social 
media users may be more concerned with the injustice or unfairness of SMA procedures (e.g., how their information is collected and analyzed) than with fulfilling the aforementioned needs via social media without incurring any costs (e.g., gains). Such perceptions of justice translate into beliefs about the overall ethicality of SMA practices, as well as the trustworthiness of organizations that perform SMA, subsequently leading to ambivalence and negative consumer responses (Brunk \& Blümelhuber, 2011; Smith et al., 2011).

\subsection{Theoretical Model and Hypotheses}

\subsubsection{Ethical Perceptions}

Ethics influence both managerial behaviors and, subsequently, managerial success (England \& Lee, 1973). Unethical behaviors or actions by organizations are those that are perceived as illegal, widely immoral and/or unjust (e.g., unfair), and hence unacceptable to the community (Jones, 1991). Consumers form overall perceptions about the ethicality of certain business actions (Crane, 2005), which can be defined as 'subjective judgments of right or wrong' or 'good or bad' (see Brunk \& Blümelhuber, 2011).

Previous research has assessed the ethicality of specific business actions or practices by capturing beliefs of rightness or wrongness, thus capturing neutral or positively/negatively valenced sentiments (Brunk \& Blümelhuber, 2011). Brunk (2010) has identified domains of corporate practices likely to elicit positive or negative ethical perceptions. Specifically, the author develops a taxonomy which involves six areas of organizational practices that trigger consumers' ethical perceptions. These areas include consumers (e.g., customer services, advertising and targeting, etc.), employees (e.g., how organizations treat their employees, health and safety procedures, etc.), environment (e.g., recycling, pollution, animal protection, etc.), overseas community (e.g., exploitation of resources), local community (e.g., moving operations abroad, community support), and business community (e.g., fair trade and sourcing, 
accounting and reporting practices, etc.) (Brunk, 2010). With regard to the 'consumers' category of the taxonomy, the author emphasizes that marketing and consumer-related activities tend to be subject to "questionable ethics" (Brunk, 2010, p. 257), in areas including pricing and labeling, targeting and advertising practices, and customer services and choice. This line of research does not address any ethical perceptions consumers have regarding market research practices, especially given the recent phenomena of big data and SMA (Le \& Liaw, 2017).

However, some recent research has highlighted the issue of companies' collecting consumer data through social media without informed consent (Punj, 2017). Companies performing SMA collect and analyze personal and brand-related information (e.g., hashtags, opinions) about their customers and other audiences (e.g., brand followers, opinion leaders) from social media sites such as Twitter, in order to better target audiences, identify new trends and/or customize online experiences (Sorokina, 2015). Nevertheless, such practices may raise ethical concerns, underpinned by views that SMA is procedurally unjust or unfair, given that it is usually done without the knowledge and consent of the consumer. More specifically, in these instances, consumers perceive unfairness in that they are not aware of and cannot control how their social media data is collected, analyzed and used, by whom and under what circumstances. For example, Twitter users are aware that the information they share may be collected for research; however, specific information is not provided (neither by the platform, nor by any other organizations performing SMA, working in partnership with Twitter), nor is there the option to opt out of such practices. Recently, Le and Liaw (2017) highlighted a set of negative effects of SMA including those relating to privacy and security; however, these authors' research did not infer or highlight the ethical aspects of such practices (e.g., Hajli \& Lin, 2016).

Still, perceptions of the unethicality of such practices are said to lead to consumer uncertainty as to whether sharing information on social media is risky, and may cause a 
potential loss of one's personal information, ideas or views (O'Keeffe \& Clarke-Pearson, 2017). Concurrently, both past (Culnan \& Bies, 2003) and recent (Punj, 2017) research into the domain of social media has posited that consumers engage in negative actions in response to those information collection practices they perceive as unethical: actions that are undesirable to companies. In particular, Culnan and Bies (2003) and Punj (2017) identify an unwillingness to disclose information and a tendency to falsify information - as well as the registering of complaints (also Hajli \& Lin, 2016; Hoadley et al., 2010)—as outcomes resulting from such unfavorable ethical perceptions. Thus, we hypothesize the following:

\section{H1: Unfavorable ethical perceptions of SMA practices lead to increased perceived} risk regarding sharing information on social media.

H2: Unfavorable ethical perceptions of SMA practices lead to a) lower consumer willingness to reveal information, b) higher likelihood of consumers taking action against organizations, and c) higher levels of falsification of information.

\subsubsection{Organizational Trustworthiness}

This concept refers to the extent to which an organization is perceived by consumers to be trustworthy and benevolent, and to possess integrity and the necessary skills and competence (Caldwell \& Clapham, 2003; Mayer \& Davis, 1999). Organizations are expected to adhere to accepted rules of conduct and to carry out certain duties, and to be honest and keep their promises so as best to serve their multiple stakeholders (Mayer, Davis \& Shoorman, 1995). While often used interchangeably with trust, trustworthiness is a perceptual antecedent of trust, which reflects an expression of faith that an institution will be reliable and fulfil its promises (Carnevale, 1995). A large body of work spanning many disciplines has assumed that trustworthiness is a belief (e.g., Gambetta, 1988; Hardin, 2002; Rotter, 1980; Yamagishi \& Yamagishi, 1994) and has linked it to the notion of perceived risk (Hansen, Saridakis \& Benson, 2018). 
Social exchange theory (SET) has often been utilized to conceptualize trustworthiness, focusing on the norm of exchange, where interactions between one party is dependent and conditional on the actions of another party (Cropanzano \& Mitchell, 2005). Trustworthiness is therefore assumed to be reciprocal (e.g., Croson \& Buchan, 1999), indicating trustors' expectations concerning the fraction to be returned. Furthermore, according to Mayer et al. (1995) and related empirical research (Caldwell \& Hayes, 2010; Hosmer, 1995; Mayer \& Davis, 1999), trustworthiness entails beliefs about the integrity, ability and benevolence of the trusted party. These beliefs are informed by justice theory, even in instances where these are not explicitly specified (Caldwell \& Clapham, 2003) and where there is no obvious interaction between two parties, such as in the case of SMA, where organizations also collect data outside the confines of customer-organizational exchange. Integrity relates to the belief that the trusted party is adhering to accepted rules of conduct, such as honesty and keeping promises. Ability, on the other hand, refers to beliefs about the skills and competence of the trusted party. Finally, benevolence is the belief that the trusted party, aside from wanting to make a legitimate profit, wants to do good to the customer (Mayer \& Davis, 1999). Additionally, trustworthiness involves a set of duties which extend to seven domains: competence, quality assurance, interactional courtesy, responsibility to inform, legal compliance, financial balance, and finally, procedural justice or fairness (Caldwell \& Clapham, 2003).

Of particular relevance to this study is trustworthiness as underpinned by procedural justice, which necessitates that key stakeholders participate and/or are represented within the organization's processes. Equally, the responsibility to inform stakeholders, such as social media users, of the organization's objectives and the procedures it uses - as well as ensuring the protection of information as part of such practices - is relevant to SMA. Thus, perceptions that an organization is not fulfilling such duties - for example, not providing information about their SMA practices (which involve the collection of consumers' information and data 
on social media) and/or using apparent procedures in doing so-may lead to uncertainty and concerns about the consequences of sharing information on social media (i.e. perceived risk), and to consumers' unwillingness to disclose information (Horne, Norberg \& Ekin, 2007). Additionally, a lack of trustworthiness will affect consumers' decisions to provide falsified information, as a protective or retaliatory behavior, given that consumers expect and trust organizations to protect their information (Punj, 2017). Such violations of trustworthiness perceptions can also lead to consumers' taking action against organizations in the form of complaints. Hence:

H3: The lower the trustworthiness, the higher the perceived risk regarding sharing information on social media

H4: The lower the trustworthiness, a) the lower the consumers' willingness to reveal information, $b$ ) the higher the likelihood of consumers' taking action against organizations, and c) the higher the levels of falsification of information.

\subsubsection{Perceived Risk of Sharing Information and Benefits}

The use of social media poses both risks and benefits to individual users. First, risk reflects the perception of the likelihood that something may go wrong, (e.g., uncertainty), as well as the perception of the seriousness of the consequences of that happening (Bettman, 1973). Perceived risk has been studied in both offline and online environments, with Garbarino and Strahilevitz (2004) highlighting fraudulent sites and the loss of privacy as online-specific risks stemming from internet usage. Generally, four types of risk have been identified as the most relevant in online contexts: privacy, performance, financial and time risk (Forsythe \& Shi, 2003; Hajli \& Lin, 2016).

Most relevant to this research is privacy risk, which relates to the probability of having private information disclosed as a result of data mining and analysis for business purposes (Garbarino \& Strahilevitz, 2004; Le \& Liaw, 2017). More specifically, privacy risk in online 
situations has been identified in relation to the provision of personal information (Hajli \& Lin, 2016; Malhotra, Kim \& Agarwal, 2004), and linked to potential losses such as theft and disclosure (Featherman, Miyazaki \& Sprott, 2010; Suh \& Han, 2003). Featherman et al. (2010) examined the perceived risk in e-services, capturing the concept as an evaluation of losses, such as privacy loss, loss of confidentiality and potential theft. Similarly, Le and Liaw (2017) captured information loss and security as aspects of privacy risk in organizational big data practices. Additionally, prior work has looked at privacy risk as a general measure of perceived risk (e.g., Malhotra et al., 2004), while other research such as Zhou (2012) has captured privacy concerns separately from perceived risk - used to denote uncertainty and consequences (e.g., losses) over the disclosure of information-positing that privacy actually impacts perceived risk.

Hansen et al. (2018) captured perceived risk in information sharing by conceptualizing and measuring the construct based on the level of overall perceived risk in sharing information, the level of uncertainty and the potential for losses. Furthermore, Hajli and Lin (2016) have examined perceived risk regarding information sharing on SNS, suggesting that such perceptions impact users' willingness to share information. Along the same lines, Punj (2017) and Hoadley et al. (2010) argue that individuals engage in a number of protective actions in order to deal with perceived risk on social media, such as refusing to share information or falsifying information. Thus:

H5: The higher the perceived risk regarding sharing information on social media, a) the lower the consumers' willingness to reveal information, $b$ ) the higher the likelihood of consumers' taking action against organizations, and c) the higher the levels of falsification of information.

However, while prior research shows that consumers perceive risks in sharing information on social media (e.g., uncertainty and consequences such as potential for loss) 
(Acquisti \& Gross, 2006; Hoadley et al., 2010), they willingly share large amounts of personal and other information on social networking sites (Madden et al., 2013; Ramasubbu, 2017). This contradiction may be explained by the fact that individuals often exhibit 'tolerance' towards certain corporate actions, because of certain perceived gains. In a qualitative study, Brunk and Blümelhuber (2011) observed that, while consumers see the unethicality of certain corporate actions, they become indifferent due to the possibility of favorable benefits. Nevertheless, this varies according to the individual and the specific corporate action, as well as the magnitude of the potential consequences or losses incurred by such actions.

More specifically, social media users understand the possibility that their information may be collected and analyzed by organizations for business purposes (Saboo et al., 2016), yet they willingly disclose information as a result of perceived benefits. These benefits can be thought in terms of the outcomes or gains that one receives (e.g., a form of distributive justice) as a result of the commercialization of social media and its leveraging by organizations in many forms (e.g., SMA and other marketing and business practices). In this case, consumers perceive a "fair exchange" or distributive justice (Culnan \& Bies, 2003), whereby the use, for example, of social media platforms (e.g., Twitter) without any financial cost is seen as a fair exchange in return for their posted sentiments or views being collected by organizations.

Furthermore, consumers may also perceive gains stemming from the practice of SMA, such as better catering to consumer needs, better service quality and, of course, customization of communications and offers. However, despite such potential benefits, consumers' willingness to disclose information on social media sites remains a function of the level of risk perceived in sharing information (uncertainty perceptions and probability of loss), where the benefits outweigh such risks (Culnan \& Bies, 2003). This means that, while consumers perceive a level of risk in sharing information on social media, this risk may or may not manifest in outcomes (e.g., unwillingness to reveal information, actions taken against 
organizations, falsifying information on social media, etc.) depending on consumers' perceptions of the benefits (e.g., distributive justice). As such we anticipate that perceived benefits will moderate the relationship between perceived risk and consumer outcomes. To this end, we hypothesize the following:

H6: Perceived benefits moderate the relationship between the perceived risk regarding sharing information on social media and a) consumers' willingness to reveal information, b) consumers' likelihood of taking against organizations, and c) levels of falsification of information.

FIGURE 1 AROUND HERE

\section{Methodology}

\subsection{Data Collection}

Data for the study were collected from 316 social media users in the UK in 2016. Participants were recruited through an online call announced on a web portal, which invited them to click on the active hypertext link to complete the questionnaire. In return for their participation, we offered respondents a completion incentive in the form of a competition for shopping vouchers. The research fully adhered to ethical research guidelines, and underwent evaluation by the university's ethics committee. The final sample's profile included $57.6 \%$ females and $42.4 \%$ males, evenly spread across the following age groups: $31 \%$ in the 18 to 24 group, $32 \%$ between 25 and 34, 30\% between 35 and 54, and $7 \%$ over 55 years of age. The majority of participants were in full-time employment (52.8\%), followed by students $(36.1 \%)$. Just slightly fewer than $40 \%$ of respondents (39.9\%) indicated education at an undergraduate level and 50.3\% had obtained a postgraduate education. The groups were well distributed across different income brackets, with $30.7 \%$ on less than $£ 10 \mathrm{~K}, 22.8 \%$ on $£ 10-19.9 \mathrm{~K}$ and 
$19 \%$ on $£ 20-29 \mathrm{~K}$. The majority of participants have been using social media for at least six years or longer (64\%), while $42 \%$ of participants spend over four hours per week on social media sites. To assess the knowledge of the respondents and to control for the variation among respondents (Wilson \& Lilien, 1992), we assured that all the responses included in the data analysis came from those respondents who were knowledgeable of, and are users of, social media sites. In addition, an assessment of respondents' knowledgeability of social media sites (i.e., Facebook and YouTube) was deemed necessary considering the relational nature of our study constructs and their proposed interrelationships. Hence, those respondents who indicated that they were not and have not previously been users of social media sites were excluded from further analysis.

\subsection{Measures}

All measures of constructs were based on previous research. Scores for all the measures were obtained on a 7-point Likert scale. Items measuring ethical perceptions of SMA practices were adapted from Hunt, Wood and Chonko (1989), while trustworthiness was captured based on Jarvenpaa et al. (1999) (e.g., keeping the best interests of the consumers in mind, revealing the truth about practices, being honest, etc.). Additionally, perceived risk, willingness to reveal information on social media, falsification, and taking actions were all taken from Malhotra et al. (2004) and are in line with current research (e.g., Hansen et al., 2018). Finally, the measure for perceived benefits was informed by Moorhead et al. (2013) and Picazo-Vela, Gutiérrez-Martínez and Luna-Reyes (2012). To test the robustness of the proposed associations and control for possible confounds, we included important extraneous variables commonly related to ethical information practices (e.g., perceptions of privacy on social media, locus of control, social networking sites' engagement 
(e.g., Fitchett \& Lim, 2008; Punj, 2017; Singh \& Hill, 2003; Vitell \& Muncy, 2005), etc.). The psychometric properties for all scales are presented in Table 1.

TABLE 1 AROUND HERE

\section{Analysis}

\subsection{Measurement Model Assessment}

Confirmatory factor analysis (CFA) of the full measurement model was run using LISREL 8.71, with the maximum likelihood estimation procedure. The measurement model achieved an acceptable model fit to the data. Specifically, the normed chi-square (i.e., $\chi^{2} /$ d.f. $\left.=155.65 / 76\right)$ of 2.04 was acceptable (Bentler \& Chou, 1987), as were the root mean square error of approximation $(\mathrm{RMSEA})=.057$; the non-normed fit index $(\mathrm{NNFI})=.961$; the comparative fit index $(\mathrm{CFI})=.972$; and the standardized root mean square residual $(\mathrm{SRMR})=.04$. Composite reliability $(\mathrm{CR})$ and average variance extracted (AVE) both exceeded the recommended standard of .60 and .50 , respectively (Bagozzi \& Yi, 1988), for each construct. To test for discriminant validity, the approach advocated by Fornell and Larcker (1981) was followed. AVEs for each construct were compared with the shared variances (squared correlations) between pairs of constructs. In all instances, the AVE values were larger than the shared variances.

To alleviate concerns regarding common method variance (CMV), both the procedural remedies and statistical tests proposed by Podsakoff, MacKenzie, Lee and Podsakoff (2003) were applied. First, we scattered the reflective items throughout the questionnaire to avoid the potential identification of items describing the same factor. Second, we used different scale formats for measuring constructs. Also, respondents were assured of a) their anonymity, and b) that there were no right or wrong answers to the questions. While these procedural remedies 
minimized the potential for common method bias, we also conducted the statistical tests proposed by Podsakoff et al. (2003). Namely, we performed Harman's single-factor test. The poor model fit $\left(\chi^{2}=1185.74 ;\right.$ d.f.=90; RMSEA=.197; NNFI=.544; CFI=.609; SRMR=.155) indicated a likely absence of CMV in our data. To further test for the potential bias in our data, we also applied the marker variable technique (Podsakoff et al., 2003). We performed a partial correlation analysis of the items measuring our constructs and assessed whether the significance of their zero-order correlations changed when the marker variable (i.e., how often do you play sports?) was partialled out. The significance of the resulting coefficients did not change, suggesting that CMV was not a problem in the analysis.

\subsection{Structural Model Assessment}

LISREL 8.71 with maximum likelihood estimation was applied to test the hypotheses. As our model also hypothesized a moderating effect of perceived benefits on the relationship between perceived risk and the three outcome variables, we initially performed a standard product-term analysis (Ping, 1995), which required the creation of a multiplicative product term and its sequential estimation in the model. Since H6 argues that the perceived benefits affect the perceived risk's relationship to the three outcome variables, a product term was created by multiplying the perceived risk with the perceived benefits. To ensure that the model was parsimonious, certain recommended procedures were followed (Aiken \& West, 1991) and the direct effect of perceived benefits was also included in the model as a control variable. Model complexity was reduced by using single item indicators for the latent variables involved in the multiplicative term (perceived risk and perceived benefits; see Ping, 1995), and by following Little, Bovaird and Widaman's (2006) procedure for orthogonalizing observed interactions. 
Further, to assess the hypothesized direct and moderating relationships, we estimated two nested structural models. In Model 1 (the constrained model), all paths from the multiplicative interaction term to the three specified outcome variables were forced to be equal to zero. In Model 2 (the unconstrained model), the structural paths between all the interaction terms and the outcome variables were freely estimated. For control purposes, in both models (the constrained and unconstrained), all the control variables were included. The fit results of the two models indicated a significant change in chi-square when moving from the constrained to the unconstrained model $\left(\mathrm{p}<.01 ; \Delta \chi^{2}=73.22\right.$; d.f.=6), along with improvements in both superior fit heuristics and in all $\mathrm{R}^{2} \mathrm{~s}$. Consequently, the unconstrained model was used for further evaluation of the hypotheses $\left(\chi^{2} /\right.$ d.f. $=305.13 / 163 ; \mathrm{CFI}=.960$; NNFI=.943; RMSEA=.053).

In $\mathrm{H} 1$, we argued that participants who have unfavorable ethical perceptions of SMA practices will have stronger perceptions of risk. Table 2 shows strong support for this hypothesis, with a significant and negative t-value ( $\mathrm{se}=-.247 ; \mathrm{p}<.01)$. Additionally, the results confirm $\mathrm{H} 3$, where a strong significant negative relationship was found between trustworthiness and perceived risk ( $\mathrm{se}=-.289 ; \mathrm{p}<.01)$. Similarly, support can be found for H5a and $\mathrm{H} 5 \mathrm{~b}$, which posit a negative relationship between the perceived risk and willingness to reveal information, and a positive relationship between perceived risk and likelihood to take action against organizations $(\mathrm{se}=-.211 ; \mathrm{p}<.05$ and $\mathrm{se}=.252 ; \mathrm{p}<.01$, respectively). Furthermore, trustworthiness negatively affects intention to falsify information $(\mathrm{se}=-.243 ; \mathrm{p}<.05)$.

No support was found for $\mathrm{H} 4 \mathrm{a}$ and $\mathrm{H} 4 \mathrm{~b}$, as no direct significant relationships exist between trustworthiness and willingness to reveal information or intention to take action against organizations. Moreover, support was not found for hypotheses $\mathrm{H} 2 \mathrm{a}, \mathrm{b}$ and $\mathrm{c}$.

In terms of the moderation effect, a diagrammatic representation in Figures $2 \mathrm{a}$ and $2 \mathrm{~b}$ provides a visual representation of the moderating effect of the perceived benefits of SMA practices on the relationship between perceived risk and the outcome variables. As shown in 
Figure 2a, as the perception of benefits increases, the negative relationship between the perceived risk and willingness to reveal information on social media (H6a) is dampened $(\mathrm{se}=.133 ; \mathrm{p}<.05)$. The results also confirm the moderating role of perceived benefits on the relationship between perceived risk and the actions users are willing to take against organizations ( $\mathrm{se}=-.159 ; \mathrm{p}<.05)(\mathrm{H} 6 \mathrm{c})$. As Figure $2 \mathrm{~b}$ shows, the positive relationship between perceived risk and actions taken is less pronounced when the perceived benefits are stronger. Finally, in testing H6b, an examination of the parameter estimate shows that the magnitude of the $t$-value associated with the benefits $\times$ perceived risk multiplicative interaction, as it relates to the likelihood of information falsification, is not significant (even though it is in the right direction; se=-.034; ns). Thus, this hypothesis is refuted.

\section{TABLE 2 AROUND HERE}

\section{FIGURES 2a, b AROUND HERE}

\subsection{Mediation Analysis}

We examined a potential mediation path between perceived ethical perceptions and trustworthiness on willingness to reveal information, likelihood of taking action and falsification of information, via perceived risk. More specifically, perceived ethical perceptions have a strong negative effect on perceived risk $(\mathrm{se}=-.247, \mathrm{p}<.01)$, while perceived risk has a strong positive impact on willingness to reveal information $(\mathrm{se}=-.211, \mathrm{p}<.05)$ and likelihood of taking action $(\mathrm{se}=.252, \mathrm{p}<.01)$, and perceived risk does not have any effect on information falsification $(\beta=-.04, \mathrm{~ns})$. This leads to significant indirect effects of perceived ethical perceptions on willingness to reveal information and likelihood of taking action, via perceived risk $(\beta$ Ethicality $\rightarrow$ Risk $\rightarrow$ Reveal $=.03, p<.05 ; \beta$ Ethicality $\rightarrow$ Risk $\rightarrow$ Action $=-.087$, $\mathrm{p}<.05$ ), providing support for the mediating function of perceived risk. As far as trustworthiness is concerned, its impact on perceived risk is strong and negative $(\beta=-.289$, 
$\mathrm{p}<.01)$. Taking into account the effect of perceived risk on the outcome variables, we conclude that significant indirect effects (via perceived risk) exist between trustworthiness and willingness to reveal information and likelihood of taking action $(\beta$ Trustworthiness $\rightarrow$ Risk $\rightarrow$ Reveal $=.037, \mathrm{p}<.05 ; \beta$ Trustworthiness $\rightarrow$ Risk $\rightarrow$ Action $=-.109$, $\mathrm{p}<.01$ ), providing support for the mediating role of perceived risk in the relationship between trustworthiness and two of the outcome variables.

\subsection{Post-Hoc Analysis}

To gain further insights into the ethicality of SMA practices and deepen our study contribution, we conducted a post-hoc analysis (Zhou, Han \& Wang, 2012). The objective was to explore whether, and to what extent, there was any correlation between the ethicality of SMA practices captured as an overall measure of ethical perceptions and as the ethical perceptions of specific SMA practices. We also investigated whether our construct of ethical perceptions of SMA practices as used in this study is sufficiently homogeneous to be adequately operationalized as a general measure of ethical perceptions of SMA. To do so, we first identified and measured facets of SMA practices based on previous research and in line with available SMA definitions (Holsapple et al., 2014; Kurniawati, Shanks \& Bekmamedova, 2013; Michaelidou, Moraes \& Micevski, 2016; Sinha, Subramanian, Bhattacharya \& Chaudhary, 2012). To get a more in-depth understanding of SMA activities that might trigger ethical connotations, we also looked at research into the domain of ethics and privacy in relation to unobtrusive research and social media (e.g., Hajli \& Lin, 2016; Hine, 2011; Martin, 2015; Moreno, van Delden, Poppe \& Reidsma, 2013; Schlegelmilch \& Öberseder, 2010; Weeden \& Williams, 2012). In doing so, we have identified domains or activities which are part of the SMA life-cycle (Holsapple et al., 2014) and which are likely to trigger ethical concerns (e.g., searching for and collecting social media data, analyzing the data, 
keeping/storing data, post-analytic activities such as selling the data, etc.). Additionally, research in the domain of ethics and SMA has indicated four areas of ethical concern: disclosure, control, consent, and exploitation of data (e.g., Colder et al., 2017; Martin, 2015).

Data were collected from 143 respondents concerning the ethical perceptions of specific SMA practices by capturing beliefs of rightness or wrongness in line with prior work on ethical perceptions (e.g., Roman, 2007; Vitell \& Muncy, 1992). Given that the rationale for the post-hoc analysis is neither to develop new measures nor to replicate the hypotheses depicted in the model, but to further establish the validity of the construct of ethical perceptions of SMA as used in this study, we focused exclusively on collecting data that served these purposes. Hence, we collected data relating to the general ethical perceptions of SMA practices, the ethical perceptions of specific SMA practices, and perceptions of risk. Participants were recruited through an online call posted on a web portal. In total, $30.8 \%$ males and $69.2 \%$ females completed the questionnaire, most belonging to the age range of 21 $40(71.9 \%)$. The majority of participants were in full-time employment (52.8\%). More than $50 \%$ of the participants had been using social networking sites for more than seven years and 75.6\% spent more than one hour per day on these sites. Hence, the sample was deemed a good reflection of the typical users of social networking sites (eMarketer, 2018; Statista, 2018).

A post-hoc analysis was conducted in order to establish the correlation between our measure of ethical perceptions of SMA practices and the ethical perceptions of specific SMA activities. First, the analysis shows a highly significant correlation between the overall ethical perceptions scale used in our study and the items of ethical perceptions of the SMA activities. Second, there is a high correlation between the ethical perceptions of specific SMA activities and perceived risk. Finally, the effects of both ethical perceptions scales on risk were quite similar, with very subtle differences. There were no significant order effects. The overall ethical perceptions measure predicted a substantial amount of variance $\left(\mathrm{R}^{2}=.27, \mathrm{~b}=.52(0.42-\right.$ 0.73), $\mathrm{t}(141)=7.24, \mathrm{p}<.001)$. The ethical perceptions of specific SMA activities explained a 
modest amount of additional variance $\left(\Delta \mathrm{R}^{2}=.03, \chi^{2}(1)=1.64, \mathrm{p}<.001, \mathrm{~b}=.17(0.03-0.43)\right.$, $t(140)=2.27, p<.005)$, with the effect of the overall ethical perceptions scale remaining significant $(\mathrm{b}=.46(0.34-0.67), \mathrm{t}(140)=5.97)$. To conclude: $a)$ the overall ethical perceptions measure (used in the model) was found to be very highly correlated with the ethical perceptions of specific SMA practices scale, as well as with its components; thus, convergent validity appears to be good and $b$ ) the ethical perceptions of specific SMA activities scale predicts little or no variance over and above the overall ethical perceptions of SMA practices scale used in the model; hence the two overlap both conceptually and statistically. This new analysis confirms the validity of using an overall ethical perceptions of SMA practices scale, thus offering a significant addition to the current literature and providing a good base for further research.

\section{Discussion and Conclusions}

Current research has focused predominantly on how organizations leverage social media for business and marketing practices (Saboo et al., 2016). Organizations attempt to solve business problems and, in doing so, they engage in social media analytics (SMA) practices (e.g., unobtrusively mining and analyzing consumer data on social media for business and marketing purposes). However, such practices have recently raised concerns as they are seen as impinging on users' privacy and control over their own information (e.g., personal data, updates, pictures, posts, opinions) (Gleibs, 2014; Palmer, 2005). Justice theory suggests that actions seen as unfair or unjust fuel ethical perceptions and perceptions of untrustworthiness, which then lead to ambivalence and negative outcomes (Culnan \& Bies, 2003).

In this study, we model outcomes of the ethical perceptions of SMA, and of trustworthiness, looking also at the roles of perceived risk in sharing information on social 
media, and benefits. The analysis has yielded theory-enhancing and managerially relevant findings, as we have identified that unfavorable ethical perceptions of SMA lead to heightened perceived risk in relation to sharing, and subsequently, to outcomes unwanted by the organization. More specifically, the results show that the impact of ethical perceptions and trustworthiness on consumers' willingness to reveal information and the likelihood to take action against organizations is mediated by the level of perceived risk in sharing information on social media. Hence, ethical perceptions of SMA practices and trustworthiness will have an impact on consumers' reaction only in instances when perceptions of uncertainty and potential loss are evoked as well. Thus, even though consumers tend to have relatively unfavorable perceptions of SMA (Mean=3.3; $\mathrm{Sd}=1.07$ on a 7-point Likert scale) and low levels of trustworthiness (Mean=3.35; $\mathrm{Sd}=1.1$ on a 7-point Likert scale), such perceptions will not manifest negative outcomes if consumers do not see uncertainty, or the potential of loss, from SMA practices. It seems, indeed, that the severity of a company's questionable behavior and the responses to it are informed by the potential of such actions to cause direct harm to the consumers (Vittel \& Muncy, 1992). Previous research, for example, has argued that consumers demonstrate tolerance and asymmetry in their ethical evaluation of corporate actions in instances in which an indirect, less immediate harm is present (Brunk, 2010). However, the presence of the potential of consequences will encourage consumers to complain and/or be unwilling to reveal information on social media. Interestingly, falsification of one's information is not affected by perceptions of ethicality. This might be due to the fact that falsification of information is an unethical conduct in its own right (Punj, 2017). The likely rationale for higher perceptions of the unethicality of these actions (by consumers) is that, as soon as any activity is actively initiated, it is judged to be unethical, whereas a passive behavior falls within the realm of acceptable behavior (Vitell \& Muncy, 2005). 
Furthermore, only trustworthiness has an impact on information falsification, showing that consumers will falsify information in instances where organizations are not perceived to be honest and truthful, and thus seen to be failing to adhere to the accepted rules of conductsuch as providing information about their SMA practices-and not taking the best interest of consumers as stakeholders into consideration in such practices (e.g., procedural and information duty) (Caldwell \& Clapham, 2003; Jarvenpaa et al., 1999). An explanation may also be found in the field of social exchange theory (SET) and the norm of reciprocity (Cropanzano \& Mitchell, 2005). In this case, trustworthiness of organizations performing SMA may be assumed to be reciprocal (e.g., Fehr \& Gächter, 2000) and more important in instances of consumer-organizational interactions (Punj, 2017). According to SET, the expectations of reciprocal returns will result in comparable contributions under the assumption that the trust between the parties involved in such exchange exists and that the obligations arising from the exchange will be fulfilled (Holmes, 1981). Perceptions of organizations not fulfilling their duties to provide information about their SMA practices, or not being honest with such information, can lead to consumers' falsifying information on social media sites.

Moreover, we found that consumers' perception of personal gains moderates the relationship between perceived risk and outcomes. Such a relationship has been intimated previously in the literature but has not received empirical confirmation (Culnan \& Bies, 2003). This highlights the significant role of consumers' perceptions of the risks to sharing information and of its potential personal benefits in organizational practices, extending previous exploratory and conceptual work on their interacting roles (Brunk \& Blümelhuber, 2011; Culnan \& Bies, 2003). Our respondents were found to be less likely to take action against organizations, and more willing to reveal information on social media platforms, where the perceived personal gains outweighed the perceived risks of the SMA practices. However, in the case of information falsification, we found no evidence of the risk/benefit 
ratio. The explanation for this might be found in the economic transactions approach to loss and gain: when a consumer negatively evaluates the cost of personal information usage, he might evaluate such costs in terms of the benefits received. However, the perceptions of risks are not evaluated as costly enough by the consumers to trigger their engagement in the falsification process (as opposed to trustworthiness). Hence the comparison process ends there; regardless of the benefits perceived, consumers will not find any justification for such actions in the risk/benefit ratio, but rather in the trustworthiness of the organization.

\subsection{Contributions, Limitations and Future Research}

This study is novel and contributes to both theory and practice. We have identified key outcomes of consumers' perceiving SMA as unethical, which organizations can take into consideration and potentially counter by increasing the perceived benefits and shaping social media users' perceptions of their organizational trustworthiness. Our contribution is significant, as the issue under investigation is both novel and timely; taking into account the existing limited research (e.g., Le \& Liaw, 2017), we have examined SMA from an ethics perspective. Our study also extends prior work concerning those corporate actions under ethical scrutiny (Brunk, 2010), providing novel and interesting knowledge of the relationship of ethical perceptions and trustworthiness to the perceived risk of sharing and consumers' protective or retaliatory outcomes. Notably, we identify the significant role of ethical SMA perceptions and trustworthiness of organizations in indirectly shaping consumers' willingness to reveal information and likelihood to take action to cause inconvenience to organizations. Last but not least, we highlight the interacting roles of perceived risk and benefits as facilitators of consumer outcomes of ethical perceptions and trustworthiness.

Our study is also managerially relevant, as we enhance the profile of ethics in the practice of SMA. Our results emphasize the importance of organizations' ensuring that they 
are seen as trustworthy, by being truthful in informing consumers about their SMA practices, reassuring them that these are safe and ethically managed procedures, and highlighting the potential benefits that may emerge from such practices to all stakeholders. Perceived personal gains from corporate actions are instrumental in leading to negative outcomes; thus, for example, organizations might inform consumers and other stakeholders that, through SMA, they are able to improve operations and better serve customers and other audiences. They should also stress, where possible, the personally relevant gains to the different stakeholders. In doing so, organizations should also emphasize the level of ethical care taken to minimize potential losses as a result of such practices.

Our study shows that consumers' reactions to the perceived unethicality of SMA practices and organizations' untrustworthiness will lead to a reaction from consumers only in instances in which such actions threaten them with immediate harm or potential loss. As such, it also has implications for policy makers. For example, consumers might be better educated concerning the magnitude of potential losses due to SMA practices, hopefully resulting in greater awareness and self-protection in SNS environments. One step towards such policy implementation has recently been proposed in the form of the General Data Protection Regulation governing data protection and privacy for all individuals within the EU, which puts the control back into the hands of the individuals in terms of personal data protection (European Commission, 2018). This is a first step not only in educating consumers of the severity of these issues, but also in making companies aware of the issue and forcing them to take action to preserve consumers' right to privacy. Additionally, improved trustworthiness perceptions and the removal of perceived risk can be achieved through institutional backing and formal contracts (Hardin, 2002). In this instance, policy makers and companies conforming to their perceived ethical and moral duties while conducting their SMA practices can boost their trustworthiness and alleviate perceived risk when engaging in these actions. 
Finally, our study is not free of limitations. While we have ensured the inclusion of relevant control variables, such as locus of control and engagement levels (e.g., exposure on social media) (Punj, 2017), there is always scope for additional factors. Thus, future research could examine, for example, past experiences and individual characteristics — such as ethical judgment, personal interests, and the integrity and honesty of individual consumers — which may impact the relationships studied in this paper. In addition, Brunk and Blümelhuber (2011) have investigated the process of creating perceptions of ethicality, identifying three types of ethical behavior that vary in their perceived intensity of impact on perceived ethicality: monovalent ethical dissatisfiers, bivalent dis/satisfiers and monovalent ethical satisfiers. Although this falls outside of the focus of this research, future research may delineate the responses to these three different sources of perceived ethicality, as they may affect the subsequent perceptions of risk associated with it and finally consumers' responses to it. This type of research is especially warranted in the context of (un)ethical social media practices, as this context is shown to differ from those of offline company practices. Concurrently, anecdotal evidence suggests that consumers are more tolerant on social media with regard to activities which may otherwise be considered unethical (Lauby, 2012). In relation to this study's context, at the time that data for this study were collected (2016), we had no reason to expect differences in perceptions of SMA processes across SNS platforms and hence have not delineated between different types of platform. Considering the recent Facebook scandal (Hsu, 2018), it might be that certain platforms are perceived as more unethical or untrustworthy. Hence, future research could investigate whether the mechanisms shown in this research differ across SNS platforms and whether the links shown are stronger or weaker depending on the platform.

Furthermore, while in line with prior research, our study examined perceived risk in terms of uncertainty and the consequences of sharing information on social media, without disclosing potential types of loss. Future research might focus on distinguishing between 
different types of loss, such as privacy loss or theft of data. Moreover, we investigated recently identified outcomes but did not distinguish between protective and retaliatory actions. Future research might choose to focus on either, or to expand to include other actions that consumers and other stakeholders may use to protect themselves and/or retaliate. Finally, even though we show in our post-hoc analysis that our measure of the ethical perceptions of SMA practices sufficiently overlaps — both conceptually and statistically — with the ethical perceptions of specific SMA activities and hence adequately captures the ethics of SMA practices, future researchers are invited to further explore how facets of SMA activities and corresponding levels of the ethical perceptions interplay with the perceived risk and behaviors of SNS users. 


\section{References}

Aiken, L. S., West, S. G., \& Reno, R. R. (1991). Multiple regression: Testing and interpreting interactions. Sage.

Acquisti, A., \& Gross, R. (2006). Imagined communities: Awareness, information sharing, and privacy on the Facebook. In Danezis G., \& P. Golle (Eds), International workshop on privacy enhancing technologies (pp. 36-58). Springer, Berlin, Heidelberg.

Ashworth, L., \& Free, C. (2006). Marketing dataveillance and digital privacy: Using theories of justice to understand consumers' online privacy concerns. Journal of Business Ethics, 67(2), 107-123.

Bagozzi, R. P., \& Yi, Y. (1988). On the evaluation of structural equation models. Journal of the academy of marketing science, 16(1), 74-94.

Bentler, P. M., \& Chou, C. P. (1987). Practical issues in structural modeling. Sociological Methods \& Research, 16(1), 78-117.

Bechwati, N. N., \& Morrin, M. (2003). Outraged consumers: Getting even at the expense of getting a good deal. Journal of Consumer Psychology, 13(4), 440-453.

Bettman (1973). Perceived risk and its components. Journal of Marketing Research, 10(2), 184-190.

Bies, R. J., \& Moag, J. S. (1986). Interactional justice: Communication criteria of fairness. Research on negotiation in organizations, 1(1), 43-55.

Brandwatch (2018a). Facebook Statistics. Available at: https://www.brandwatch.com/blog/47-facebook-statistics/ [Accessed: September 2018]. Brandwatch (2018b). Social Media Statistics. Available at:

https://www.brandwatch.com/blog/amazing-social-media-statistics-and-facts/ [Accessed: September 2018]. 
Brunk, K. H. (2010). Exploring origins of ethical company/brand perceptions. A consumer perspective of corporate ethics. Journal of Business Research, 63(3), 255-262.

Brunk, K. H., \& Blümelhuber, C. (2011). One strike and you're out: Qualitative insights into the formation of consumers' ethical company or brand perceptions. Journal of Business Research, 64(2), 134-141.

Caldwell, C. \& Clapham, S.E. (2003). Organizational trustworthiness: An International perspective. Journal of Business Ethics, 47(4), 349-364.

Caldwell, C., Hayes, L. A. (2010). Leadership, Trustworthiness, and Ethical Stewardship. Journal of Business Ethics, 96(4), 497-512.

Carnevale, D. G. (1995). Trustworthy Government: Leadership and Management Strategies for Building Trust and High Performance. Jossey-Bass Publishers, San Francisco, CA.

Cohn, D.Y. (2001). Commentary essay on "exploring origins of ethical company/brand perceptions - a consumer perspective of corporate ethics". Journal of Business Research 63(12), 1267-1268.

Colder, S., Shahd, A., Gill, N., \& Booth, A., (2017). Attitudes toward the ethics of research using social media: A systematic review. Journal of Medical Internet Research, 19(6), 195.

Courtois, C., Mechant, P., De Marez, L., \&Verleye, G. (2009). Gratifications and seeding behavior of online adolescents. Journal of Computer-Mediated Communication, 15(1), 109-137.

Crane A. (2005). Meeting the ethical gaze: challenges for orienting to the ethical market. In: Harrison R, Newholm T, Shaw D. (Eds.), The Ethical Consumer (pp. 219-32). London: Sage.

Cropanzano R \& Mitchell, M.S. (2005). Social exchange theory: An interdisciplinary review. Journal of Management, 31(6), 874-900. 
Croson, R., \& Buchan, N. (1999). Gender and Culture: International Experimental Evidence from Trust Games. American Economic Review, 89(2), 386-391.

Culnan, M. J., \& Armstrong, P. K. (1999). Information privacy concerns, procedural fairness, and impersonal trust: An empirical investigation. Organization science, 10(1), 104-115.

Culnan, M. J., \& Bies, R. J. (2003). Consumer privacy: Balancing economic and justice considerations. Journal of Social Issues, 59(2), 323-342.

DiStaso, M.W. \& Bortree D. (2014). Ethical Practice of Social Media in Public Relations. Routledge.

Dua, T. (2016). Brands have started using Twitter's latest customer service tools. Available at: https://digiday.com/marketing/brands-started-using-twitters-latest-customer-service-tools/ [Accessed September 10, 2018].

England, G. W., \& Lee, R. (1973). Organization size as an influence on perceive organizational goals: A comparative study among American, Japanese, and Korean managers. Organizational Behavior and Human Performance, 9(1), 48-58.

Ennew, C., \& Sekhon, H. (2007). Measuring trust in financial services: The trust index. Consumer Policy Review, 17(2), 62.

Emarketer (2018). Time Spent with Media Plateaus in UK. Available at: https://www.emarketer.com/content/time-spent-with-media-plateaus-in-uk [Accessed September 13, 2018].

Featherman, M. S., Miyazaki, A. D., \& Sprott, D. E. (2010). Reducing online privacy risk to facilitate e-service adoption: the influence of perceived ease of use and corporate credibility. Journal of Services Marketing, 24(3), 219-229.

Fehr, E., \& Gächter, S. (2000). Fairness and retaliation: The economics of reciprocity. Journal of economic perspectives, 14(3), 159-181. 
Fitchett, J., \& Lim, M. (2008). Consumer experiences in the "house of the future": An enquiry into surveillance-based consumer research techniques. Consumption, Markets and Culture, 11(2), 137-149.

Fornell, C., \& Larcker, D. F. (1981). Evaluating structural equation models with unobservable variables and measurement error. Journal of Marketing Research, 18(1), 39-50.

Forsythe, S. M. \& Shi, B. (2003). Consumer patronage and risk perceptions in Internet shopping. Journal of Business Research, 56(11), 867-875.

Gambetta, D. (1988). Making and breaking cooperative relations. Blackwell.

Garbarino, E., \& Strahilevitz, M. (2004). Gender differences in the perceived risk of buying online and the effects of receiving a site recommendation. Journal of Business Research, 57(7), 768-775.

GDPR (2018). The EU General Data Protection Regulation. Available at: https://eugdpr.org/ [Accessed September 9, 2018].

Gleibs, I. H. (2014). Turning virtual public spaces into laboratories: Thoughts on conducting online field studies using social network sites. Analyses of Social Issues and Public Policy, $14(1), 352-370$.

Gregoire Y., \& Fisher, R. J. (2008). Customer betrayal and retaliation: when your best customers become your worst enemies. Journal of the Academy of Marketing Science, 36, 247-261.

Gross, C. (2008). A measure of fairness: An investigative framework to explore perceptions of fairness and justice in a real-life social conflict. Human Ecology Review, 15(2), 130140.

Güth, W., Schmittberger, R., \& Schwarze, B. (1982). An experimental analysis of ultimatum bargaining. Journal of economic behavior \& organization, 3(4), 367-388. 
Hajli, N., \& Lin, X. (2016). Exploring the security of information sharing on social networking sites: The role of perceived control of information. Journal of Business Ethics, 133(1), 111-123.

Hansen, J. M., Saridakis, G., \& Benson, V. (2018). Risk, trust, and the interaction of perceived ease of use and behavioral control in predicting consumers' use of social media for transactions. Computers in Human Behavior, 80, 197-206.

Hardin, R. (2002). Trust and trustworthiness. Russel Sage Foundation. New York.

Heath, D., Koch, E., Ley, B., \& Montoya, M. (1999). Nodes and queries: Linking locations in networked fields of inquiry. American Behavioral Scientist, 43(3), 450-463.

Hine, C. (2011). Internet research and unobtrusive methods. Social Research Update 61, University of Surrey.

Hoadley, C. M., Xu, H., Lee, J. J., \& Rosson, M. B. (2010). Privacy as information access and illusory control: The case of the Facebook news feed privacy outcry. Electronic Commerce Research and Applications, 9(1), 50-60.

Holmes, J.G. (1981). The exchange process in close relationships. The justice motive in social behavior. Springer.

Holsapple, C., Hsiao, S. H., \& Pakath, R. (2014). Business social media analytics: definition, benefits, and challenges. In Proceedings of the Americas Conference on Information Systems 2014 (pp. 1-12). Savannah, GA.

Horne, D. R., Norberg, P. A., \& Ekin, C. A. (2007). Exploring consumer lying in informationbased exchanges. Journal of Consumer Marketing, 24(2), 90-99.

Hosmer, L. T. (1995). Trust: The connecting link between organizational theory and behavior. Academy of Management Review 20(2), 379-404.

Hsu, T. (2018). For Many Facebook Users, a 'Last Straw' That Led Them to Quit. Available at: https://www.nytimes.com/2018/03/21/technology/users-abandon-facebook.html [Accessed August 30, 2018]. 
Hudson, S., Huang, L., Roth, M.S., Madden, T.J. (2016). The influence of social media interactions on consumer-brand relationships: A three-country study of brand perceptions and marketing behaviors. International Journal of Research in Marketing, 33(1), 27-41.

Hunt, S. D., Wood, V. R., \& Chonko, L. B. (1989). Corporate ethical values and organizational commitment in marketing. The Journal of Marketing, 53(3), 79-90.

IPA (2018). Adults spend almost 8 hours each day consuming media. Available at: http://www.ipa.co.uk/news/adults-spend-almost-8-hours-each-day-consumingmedia\#.W5uRb mxV1t [Accessed September 13, 2018].

Jarvenpaa, S. L., Tractinsky, N., \& Saarinen, L. (1999). Consumer trust in an internet store: a cross-cultural validation. Journal of Computer-Mediated Communication, 5(2), 1-35.

Jones, T. M. (1991). Ethical decision making by individuals in organizations: An issue contingent model. Academy of Management Review, 16(2), 366-395.

Kurniawati, K., Shanks, G. G., \& Bekmamedova, N. (2013). The Business Impact of Social Media Analytics. In Proceedings of the $21^{\text {st }}$ European Conference on Information Systems (pp. 48-61). Utrecht, Netherlands.

Lauby, S. (2012). Ethics and social media: Where should you draw the line? Available at: https://www.americanexpress.com/us/small-business/openforum/articles/ethics-andsocial-media-where-should-you-draw-the-line/ [Accessed September 9, 2018].

Le, T. M. \& Liaw (2017). Effects of Pros and Cons of Applying Big Data Analytics to Consumers' Responses in an E-Commerce Context. Sustainability. 9(5), 798.

Little, T. D., Bovaird, J. A., \& Widaman, K. F. (2006). On the merits of orthogonalizing powered and product terms: Implications for modeling interactions among latent variables. Structural Equation Modeling, 13(4), 497-519.

Macklin, R., Martin, A., \& Mathison, K. (2015). An integrated model of justice and ethical climates and the influence of cultural diversity. Management and Organization Review, $11(1), 101-121$. 
Madden, M., Lenhart, A., Cortesi, S., Gasser, U., Duggan, M., Smith, A., \& Beaton, M. (2013). Teens, social media, and privacy. Pew Research Center, 21, 2-86.

Malhotra, N. K., Kim, S. S., \& Agarwal, J. (2004). Internet users' information privacy concerns (IUIPC): The construct, the scale, and a causal model. Information Systems Research, 15(4), 336-355.

Mander, J. (2015). Half of Instagrammers follow brands. Available at: https://blog.globalwebindex.net/chart-of-the-day/half-of-instagrammers-follow-brands/ [Accessed on September 30 $0^{\text {th }}$, 2017].

Martin, K. (2015). Understanding privacy online: Development of a social contract approach to privacy. Journal of Business Ethics 137(3), 551-569.

Mayer, R. C., \& Davis, J. H. (1999). The effect of the performance appraisal system on trust for management: A field quasi-experiment. Journal of Applied Psychology, 84(1), 123136.

Mayer, R. C., Davis, J. H., \& Schoorman, F. D. (1995). An integrative model of organizational trust. Academy of management review, 20(3), 709-734.

Michaelidou N., Christodoulides G., \& Kilic U. (2016). Developing a Brand Talkativeness Scale. In Obal M., Krey N., \& C. Bushardt (Eds), Let's Get Engaged! Crossing the Threshold of Marketing's Engagement Era. Developments in Marketing Science: Proceedings of the Academy of Marketing Science (pp. 53-56). Springer, Cham. Michaelidou, N., Moraes, C., \& Micevski, M. (2016). A Scale for Measuring Consumers' Ethical Perceptions of Social Media Research. In Obal M., Krey N., \& C. Bushardt (Eds), Let's Get Engaged! Crossing the Threshold of Marketing's Engagement Era (pp. 97-100). Springer, Cham.

Moorhead, S. A., Hazlett, D. E., Harrison, L., Carroll, J. K., Irwin, A., \& Hoving, C. (2013). A new dimension of health care: systematic review of the uses, benefits, and limitations of social media for health communication. Journal of medical Internet research, 15(4). 
Moreno, A., van Delden, R., Poppe, R., \& Reidsma, D. (2013). Socially aware interactive playgrounds. IEEE pervasive computing, 12(3), 40-47.

O'Keeffe, G. \& Clarke-Pearson, K. (2011). The impact of social media on children, adolescents and families. Pediatrics, 127(4), 800-804.

Palmer, D. E. (2005). Pop-Ups, cookies, and spam: toward a deeper analysis of the ethical significance of Internet marketing practices. Journal of Business Ethics, 58, 271-280.

Picazo-Vela, S., Gutiérrez-Martínez, I., \& Luna-Reyes, L. F. (2012). Understanding risks, benefits, and strategic alternatives of social media applications in the public sector. Government information quarterly, 29(4), 504-511.

Ping Jr, R. A. (1995). A parsimonious estimating technique for interaction and quadratic latent variables. Journal of Marketing Research, 32, 336-347.

Podsakoff, P. M., MacKenzie, S. B., Lee, J. Y., \& Podsakoff, N. P. (2003). Common method biases in behavioral research: a critical review of the literature and recommended remedies. Journal of applied psychology, 88(5), 879.

Punj (2017). Consumer intentions to falsify personal information online: unethical or justifiable? Journal of Marketing Management, 33(15-16), 1402-1412.

Ramasubbu, S. (2017). Influence of social media on teenagers. Available at: https://www.huffingtonpost.com/suren-ramasubbu/influence-of-social-media-onteenagers_b_7427740.html?guccounter=1 [Accessed September 6, 2018].

Roman, S. (2007). The ethics of online retailing: a scale development and validation from the consumers' perspective. Journal of Business Ethics, 72(2), 131-148.

Rotter, J. B. (1980). Interpersonal trust, trustworthiness, and gullibility. American Psychologist, 35(1), 1-7.

Rupp, D. E., Wright, P. M., Aryee, S., \& Luo, Y. (2015). Organizational justice, behavioral ethics, and corporate social responsibility: Finally the three shall merge. Management and Organization Review, 11(1), 15-24. 
Saboo, A. R, Kumar, V., \& Ramani, G. (2016). Evaluating the impact of social media activities on human brand sales. International Journal of Research in Marketing, 33, 524541.

Schlegelmilch, B. B., \& Öberseder, M. (2010). Half a century of marketing ethics: Shifting perspectives and emerging trends. Journal of Business Ethics, 93(1), 1-19.

Singh, T., \& Hill, M. E. (2003). Consumer privacy and the Internet in Europe: a view from Germany. Journal of consumer marketing, 20(7), 634-651.

Sinha, V., Subramanian, K. S., Bhattacharya, S., \& Chaudhary, K. (2012). The contemporary framework on social media analytics as an emerging tool for behavior informatics, HR analytics and business process. Management, 17(2), 65-84.

Smith, A. N., Fischer, E., \&Yongjian, C. (2012). How does brand-related user-generated content differ across YouTube, Facebook, and Twitter? Journal of Interactive Marketing, 26(2), 102-113.

Smith, H. J., Dinev, T., \& Xu, H. (2011). Information privacy research: an interdisciplinary review. MIS quarterly, 35(4), 989-1016.

Sorokina, O. (2015). How to make social media data work for you. Available at: https://blog.hootsuite.com/social-media-data/ [Accessed on November 5, 2017].

Statista (2018). Social Media Statistics \& Facts. Available at: https://www.statista.com/topics/1164/social-networks/ [Accessed September 13, 2018].

Suh, B., \& Han, I. (2003). The IS risk analysis based on a business model. Information \& Management, 41(2), 149-158.

Vitell, S. J., \& Muncy, J. (1992). Consumer ethics: An empirical investigation of factors influencing ethical judgments of the final consumer. Journal of Business Ethics, 11(8), $585-597$.

Vitell, S. J., \& Muncy, J. (2005). The Muncy-Vitell consumer ethics scale: A modification and application. Journal of Business Ethics, 62(3), 267-275. 
Weeden, M. R., \& Williams, G. (2012). Ethics and on-line research methodology. Journal of Social Work Values and Ethics, 9(1), 40-51.

Wilson, E. J., \& Lilien, G. L. (1992). Using single informants to study group choice: An examination of research practice in organizational buying. Marketing Letters, 3(3), 297 305.

Xu, H., Teo, H. H., Tan, B. C., \& Agarwal, R. (2009). The role of push-pull technology in privacy calculus: the case of location-based services. Journal of Management Information Systems, 26(3), 135-174.

Yamagishi, T., \& Yamagishi, M. (1994). Trust and commitment in the United States and Japan. Motivation and Emotion, 18(2), 129-166.

Zhang, J., \& Mao, E. (2016). From Online Motivations to Ad Clicks and to Behavioral Intentions: An Empirical Study of Consumer Response to Social Media Advertising. Psychology \& Marketing, 33(3), 155-164.

Zhou, T. (2012). Examining location-based services usage from the perspectives of unified theory of acceptance and use of technology and privacy risk. Journal of Electronic Commerce Research, 13(2), 135.

Zhou, X., Han, Y., \& Wang, R. (2012). An empirical investigation on firms' proactive and passive motivation for bribery in China. Journal of Business Ethics, 118(3), 461-472. 